\title{
RESENHA
}

\section{SILVA, Maria da Conceição Fonseca. Questôes de linguagem: gramática, texto e discurso. Vitória da Conquista: UESB, 2001. 116p.}

\author{
Elisângela Gonçalves da Silva \\ Universidade Estadual do Sudoeste da Bahia
}

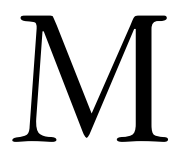

aria da Conceição Fonseca Silva é professora de Lingüística do Departamento de Estudos Lingüísticos e Literários da Vitória da Conquista. Graduou-se em Letras Vernáculas pela Universidade Estadual do Sudoeste da Bahia, é mestre em Lingüistica, na Área de Análise do Discurso, pela UNICAMP e está doutorandose em Lingüística, na mesma área e Instituição. Suas publicações têm tematizado questões referentes a gramática, texto e discurso.

O seu livro Questões de linguagem: gramática, texto e discurso constitui-se de apresentação e oito ensaios. 
Na Apresentação, a autora esclarece ser o livro resultado de alguns ensaios redigidos entre 1991 e início de 2000 e afirma objetivar que o leitor trilhe o seu caminho, na busca de compreender algumas questões de linguagem.

O texto Gramática: uma questão a reveré fruto das discussões realizadas em torno da inquietação de lingüistas, professores e alunos, com relação à ineficácia do ensino gramatical, na disciplina "Língua Portuguesa VIII", no Curso de Letras na Universidade Estadual do Sudoeste da Bahia, no I Semestre de 1991.

Silva, nesse ensaio, tem em vista apontar que a realidade gramatical atual é decorrente de uma tradição constituída durante vinte e três séculos. Para tanto, aborda a gramática tradicional historicamente. Além disso, analisa criticamente o modo como a gramática é ensinada nas escolas, a despeito de estudos e contribuições diversas de lingüistas. São apresentadas acepções do termo gramática (descritiva, internalizada, gerativa, tradicional) e questões, como a deficiência na formação lingüística do professor. Orientações pedagógicas equivocadas são levantadas; e as atividades lingüísticas (o falar a língua), epilingüísticas (o trabalhar a língua) e metalingüísticas (o falar sobre a língua) são tematizadas.

Para obterem-se informações acerca do ensino das gramáticas nas escolas, foi elaborado e aplicado um questionário a vinte e dois docentes de Língua Portuguesa de $1^{\circ}$ e $2^{\circ}$ graus da comunidade de Vitória da Conquista. Verificou-se que a maioria dos professores entrevistados, dentre outras coisas, ensina a gramática com finalidades normativa e teórica, de modo a levar o aluno a falar e escrever corretamente, sendo o conceito de gramática adotado o seguinte: "conjunto de regras que deve ser seguido por aqueles que querem falar e escrever corretamente." (p. 17) Logo, os conteúdos que considera importantes são ortografia, acentuação, pontuação, classes de palavras..., pois "possibilitam escrever melhor; são básicos; eliminam problemas concernentes à escrita”. (p. 21) Ademais, a maioria considera importante a definição de entidades gramaticais, uma vez que ajuda a fixar melhor e facilita a aprendizagem. 
Em Textos orais e textos escritos, são mostradas as diferenças formais e funcionais concernentes aos textos orais e escritos. De acordo com nota de rodapé, a reflexão feita não considera os hipertextos, nem a interação sócio-comunicativa de salas de batepapo da Internet e de programas, como ICQ, Combc, entre outros, em que a interação pode acontecer em tempo real.

No que se refere às diferenças funcionais, a doutoranda historia sucintamente a trajetória da escrita e da oralidade e a importância que cada uma assume nas diferentes sociedades e épocas, correspondendo ao modo de vida dos povos.

Os fatores envolvidos na produção de sentido do texto falado ou escrito são considerados no texto Fator de textualidade: $a$ coerência do que depende? Silva, a partir das propostas de Koch e Travaglia (1989), por um lado, e de Van Dijk (1980, 1983, 1985), de outro, apresenta uma nova proposta:

"Feitas essas considerações é possível chegarmos a outra proposta. A textualidade tem como fator único a coerência, que é o resultado da construção do significado.

Mas o estabelecimento da coerência, por sua vez, depende de fatores interdependentes, que fazem parte do conhecimento de mundo dos interlocutores: os estruturais: superestrutura, macroestrutura, microestrutura; e os pragmáticos: situacionalidade, intencionalidade, informatividade, intertextualidade e aceitabilidade." (p. 41)

Em nota de rodapé, esclarece que, embora Koch e Travaglia não considerem a super e a macroestrutura fatores colaboradores do estabelecimento da coerência, na obra O texto e a construção dos sentidos, Koch (1997) refere-se a esses fatores como conhecimento metacognitivo, os quais são acessados durante o processamento do texto.

A autora insiste que um texto (falado ou escrito) se funda na interação entre os interlocutores.

É feita uma análise da função discursiva do mecanismo de coesão lexical ${ }^{1}$ no ensaio Elementos lexicais: função discursiva, além da função coesiva. Para tanto, é utilizado um texto de Oliveira (1997). 
Ao analisar esse texto, demonstra muito bem que os elementos lexicais, além das funções coesivas, possuem também funções discursivas. Silva busca aplicar em sua análise parte dos elementos de coesão tratados por Halliday e Hasan (1976), autores que, conforme ela, "tornam-se os expoentes teorizadores da coesão, colocando esta propriedade como determinante parcial da textura." (p. 62)

A ensaísta mostra que, de fato, os elementos coesivos lexicais possuem dupla função: a) mantêm a relação entre elementos no seio do texto (conforme afirmam Halliday e Hasan) e b) "funcionam, também, como elementos de saber de uma determinada formação discursiva, produzindo efeitos de sentidos determinados por essa formação discursiva" (p.66), orientando o interlocutor na interpretação do referente e da posição discursiva do locutor.

O texto $A$ discursividade de gênero em Claudia : o mesmo e o outro no caso "Uma ofensa à mulber" foi elaborado a partir da dissertação de mestrado da autora, intitulada Discursos de gênero em revistas femininas: o caso Claudia.

Num trabalho profundo e detalhado, a analista do discurso compara o discurso que permeia a matéria da revista Claudia, Uma ofensa à mulher, editada em março de 1998, nas páginas 42 e 43, ao que está presente em anúncios publicitários da DuLoren, que são alvo de críticas negativas na referida matéria. Silva trabalha com o referencial teórico, conceptual e epistemológico da Análise do Discurso Francesa associado a alguns deslocamentos da Teoria Polifônica da Enunciação.

São apresentados nesse ensaio: análise e discussão da matéria da revista Claudia, Uma ofensa à mulher, um anúncio publicitário publicado em um exemplar dessa revista antes dessa matéria e outro anúncio editado posteriormente a ela; cartas de leitores emitindo opiniões sobre a matéria Uma ofensa à mulher na própria revista, na seção Sua opinião, em edições posteriores a março de 1998.

A ensaísta constata que, sob a aparência da mudança, a revista Claudia legitima e realimenta a desigualdade das relações de gênero, uma vez que a revista 
"refuta o saber adverso por questões morais e religiosas, pois os mesmos discursos de gênero presentes nos anúncios publicitários da empresa DuLoren estão presentes em anúncios publicitários veiculados antes e depois da matéria Uma ofensa à mulher.” (p.77)

No texto Retorno do Sujeito no sujeito na discursividade de gênero, com base nos pressupostos teórico-metodológicos da Análise do Discurso Francesa, são realizadas análise e discussão de dois anúncios publicitários da revista Claudia, de maio de 1997, na tentativa de explicitar efeitos de sentido ou "momentos de interpretação". Ao levar em conta que o texto publicitário constrói-se a partir de vários domínios semióticos, a autora considera em sua análise não apenas a materialidade lingüística, como também outros domínios que se apresentam interdependentes. Os vários domínios semióticos presentes nos anúncios "funcionam, por sua vez, como "pontos de deriva possíveis' que ajudam na construção dos significados.” (p.89) Se fossem considerados apenas os elementos lingüísticos, poderiam ser evitados riscos provenientes de qualquer tentativa de uma prática discursiva intersemiótica; entretanto, por outro lado, poder-se-ia distanciar de uma prática discursiva que, além de integrar a materialidade lingüística que se inscreve na história, integra a materialidade oriunda de outros domínios semióticos (como pictural), que também se inscrevem na história.

Ademais, são mobilizados alguns conceitos-chave da Análise do Discurso: sujeito, formações discursivas, formações ideológicas, interdiscursos, prática discursiva.

A base teórica que norteia a autora no texto O fenômeno da interincompreensão constitutiva em cartas de leitores são os pressupostos epistemológicos de Maingueneau (1984), sobretudo a consideração deste no concernente à Polêmica como interincompreensão.

A fim de analisar e verificar o efeito dos aspectos abordados da teoria do discurso de Maingueneau, Silva apresenta algumas cartas de leitores contidas na revista Claudia, na seção Sua opinião, em exemplares publicados em 1999 e 2000. Tal seção, conforme a ensaísta, corresponde a aproximadamente 0,9\% das páginas da revista. 
Ainda que nessas cartas os leitores, em sua maioria, manifestem opiniões favoráveis aos artigos publicados em Claudia, alguns direcionam-se para outras posições discursivas, e a revista não pode deixar de publicá-las.

É nesse espaço discursivo que a analista do discurso busca mostrar a interdiscursividade "como um processo de tradução e interpretação generalizadas do outro em seu simulacro, ligado ao fenômeno da interincompreensão constitutiva." (p. 96, grifos da autora)

Apresenta-se em Os gestos de interpretação da Constituição Brasileira de 1998 um breve histórico sobre a gênese das constituições, assim como a definição de constituição (nas considerações iniciais).

No decurso do texto são respondidos os seguintes questionamentos: "Como se dá o controle de constitucionalidade?" e "Como se regulam os gestos de interpretação da Constituição de 1988?".

Em seu livro Questões de linguagem: gramática, texto e discurso, Silva utiliza uma linguagem clara e, além disso, é muito objetiva e sucinta em suas abordagens. É importante a apresentação de referências bibliográficas no final de cada um dos ensaios, visto que isso constitui um estímulo para que o leitor venha a expandir o conhecimento sobre o assunto tratado. Outro fator importante é o de a autora consultar a própria fonte (como Roulet, Luria, Bakthin, Beaugrande e Dressler, Foucault, Halliday e Hasan, Pêcheux, Van Dijk, Maingueneau, entre outros), em vez de citá-la por terceiros.

Tenho algumas considerações a fazer sobre alguns ensaios. No texto Elementos lexicais: função discursiva, além da função coesiva é feita uma análise diferente e importante, sob o ponto de vista da Análise do Discurso, visto que normalmente análises desse tipo são feitas a partir das considerações da Lingüística Textual. É muito interessante a relação demonstrada pela autora entre coesão e função discursiva. Concordo em absoluto com Pêcheux - citado pela autora quanto ao fato de o locutor de um dado texto sempre deixar transparecer a posição social por ele ocupada, a sua formação discursiva. Também sou inteiramente favorável às colocações apontadas no ensaio $A$ discursividade de gênero em Claudia : o mesmo e o outro no caso "Uma ofensa à mulher". 
Também tenho algumas sugestões a registrar. No texto $O$ fenômeno da interincompreensão constitutiva em cartas de leitores, acredito haver a necessidade de explicitar aos leitores o significado da sigla GEL. Provavelmente, devido ao material utilizado na impressão, as figuras 1 (p. 72) e 2 (p. 74) apresentam-se escuras, o que dificulta um pouco a sua leitura. Numa próxima edição, faz-se necessário rever essa questão. Uma outra sugestão à Editora é que, enquanto não se proceda a uma nova edição, seja feita uma errata de alguns termos.

Inquestionavelmente, este é um texto a ser lido por profissionais da Área de Letras e Lingüística, desde docentes até estudantes de graduação e pós-graduação. Também será de grande proveito para docentes de Língua Portuguesa de nível fundamental e médio, sobretudo no tocante às questões relativas a gramática, textos orais e escritos, fatores de textualidade. É estimulante o convite feito pela autora a todos que, de alguma maneira, tenham interesse pelas questões relativas à linguagem para constituir seu conhecimento, vez que seu objetivo (da autora) não é "fechar as portas", mas lançar o fio para que os outros o apanhem e continuem a tecer.

\section{NOTA}

${ }^{1}$ Silva justifica a escolha de tal função por ser a que apresenta maior quantidade de indicações para análise do discurso. 


\section{REFERÊNCIAS BIBLIOGRÁFICAS}

BAKTHIN, M. La poetique de Dostoievski. Paris: Senil, 1970. 346 p.

BEAUGRANDE, R. A.; DRESSLER, W. U. Introduction to text linguistics. Londres: Longman, 1981. 246 p.

FOUCAULT, M. A ordem do discurso: aula inaugural no Collège de France, pronunciada em 2 de dezembro de 1970. São Paulo: Edições Loyola, 1996. 79 p. Edição original 1971.

HALLIDAY, M. A. K.; HASAN, R. Cohesion in English. London: Longmam, 1976. $374 \mathrm{p}$.

KOCH, I. G. V. O texto e a construção de sentidos. São Paulo: Ática, 1997. 124 p. ;; TRAVAGlia, L. C. Texto e coerência. São Paulo: Cortez, 1989. 94 p.

LURIA, A. R. Pensamento e linguagem: as últimas conferências de Luria. Porto Alegre: Artes Médicas, 1986. 251 p.

MAINGUENEAU, D. La polemique comme interincompréhension. In:

Genèses du discours. Bruxelles: P. Madarga, 1984, p. 109-33.

OLIVEIRA, S. D. de. ISTOÉ, São Paulo, n. 1444, p. 59, 4 jun. 1997.

PECHEUX, M. Análise automática do discurso. In: GADET, F.; HAK, T. (Org.). Por uma análise automática do discurso: uma introdução à obra de Pêcheux. Trad. Bethania S. Mariani et al. Campinas: Ed. da UNICAMP, 1990, p. 61-105. (título original, 1969).

. O discurso: estrutura ou acontecimento? Trad. Eni P. Orlandi. São Paulo: Pontes, 1990. 68 p. Edição original: 1983.

. Semântica e discurso: uma crítica à afirmação do óbvio. Trad. Eni P. Orlandi et al. Campinas: Ed. da UNICAMP, 1988. 317 p. Edição original: 1975.

ROUlET, E. Teorias lingüísticas, gramáticas e ensino de linguas. São Paulo: Contexto, 1987. 129 p.

VAN DIJK, T. A. Texto y contexto. Trad. Sibila Hunzinger. Madrid: Cátedra, 1980. $357 \mathrm{p}$.

Discourse and communication. New approaches to the analysis of mass media discourse and communication. Berlin: Gruyter, 1985. 285 p. 